Sarah Caroline Valcácio Campos

\title{
O impacto das condições financeiras na atividade e sua relevância na transmissão da política monetária
}

Dissertação apresentada como requisito parcial para obtenção do grau de Mestre pelo Programa de Pós-graduação em Macroeconomia e Finanças, do Departamento de Economia da PUCRio.

Orientador: Prof. Tiago Couto Berriel 


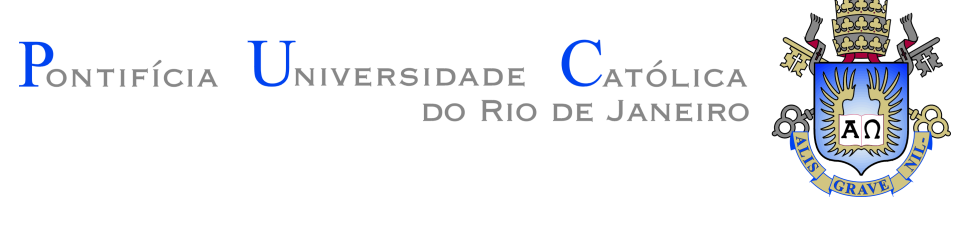

Sarah Caroline Valcácio Campos

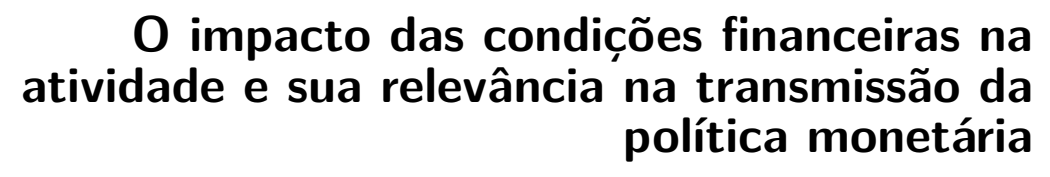

O impacto das condições financeiras na política monetária

Dissertação apresentada como requisito parcial para obtenção do grau de Mestre pelo Programa de Pós-graduação em Macroeconomia e Finanças da PUC-Rio. Aprovada pela Comissão Examinadora abaixo:

\author{
Prof. Tiago Couto Berriel \\ Orientador \\ Departamento de Economia - PUC-Rio
}

Prof. Marcelo Cunha Medeiros

Departamento de Economia - PUC-Rio

Prof. Waldyr Dutra Areosa

Departamento de Economia - PUC-Rio

Rio de Janeiro, 3 de Setembro de 2020 
Todos os direitos reservados. A reprodução, total ou parcial do trabalho, é proibida sem a autorização da universidade, do autor e do orientador.

\section{Sarah Caroline Valcácio Campos}

Graduou-se em Economia pelo IBMEC (Instituto Brasileiro de Mercado de Capitais) no ano de 2015.

Ficha Catalográfica

Campos, Sarah Caroline Valcácio

O impacto das condições financeiras na atividade e sua relevância na transmissão da política monetária / Sarah Caroline Valcácio Campos; orientador: Tiago Couto Berriel. 2020.

$38 \mathrm{f:}$ il. color. ; $30 \mathrm{~cm}$

Dissertação (mestrado) - Pontifícia Universidade Católica do Rio de Janeiro, Departamento de Economia , 2020.

Inclui bibliografia

1. Macroeconomia - Teses. 2. Condições Financeiras. 3. FCI. 4. FAVAR. 5. VAR. 6. Política Monetária. I. Berriel, Tiago Couto. II. Pontifícia Universidade Católica do Rio de Janeiro. Departamento de Economia . III. Título.

CDD: 330 


\section{Agradecimentos}

À Deus, que permitiu cada passo até aqui.

Aos meus pais, Luiz Carlos e Angélica, por todas as palavras de apoio. Obrigada por me ensinarem a buscar o meu melhor todos os dias. Vocês são os meus maiores exemplos.

Aos meus amigos e, em especial, ao André Rodrigues. O caminho é muito mais leve com você ao lado. Obrigada por ser paz em meio à tanta ansiedade e por sempre acreditar em mim.

Ao meu orientador, Tiago Berriel. Agradeço ao suporte e ensinamentos durante este período.

À Novus Capital, pelo suporte financeiro. É uma honra trabalhar ao lado de pessoas que te incentivam na busca pelo conhecimento. 


\section{Resumo}

Campos, Sarah Caroline Valcácio; Berriel, Tiago Couto. O impacto das condições financeiras na atividade e sua relevância na transmissão da política monetária. Rio de Janeiro, 2020. 38p. Dissertação de Mestrado - Departamento de Economia , Pontifícia Universidade Católica do Rio de Janeiro.

O objetivo deste estudo consiste em analisar o efeito das condições financeiras sobre a atividade econômica e entender o papel destas na transmissão da política monetária. Nossas evidências sugerem que, no caso dos Estados Unidos, um aperto nas condições financeiras possui efeito bastante similar a um choque contracionista de juros. Apesar disso, ao controlarmos a taxa de juros para o FCI, os resultados indicam que inovações de política monetária não atuam através das condições financeiras. Tal conclusão, no entanto, não pode ser generalizada para outros países. Encontramos que, no caso do Canadá, as condições financeiras possuem relevância na transmissão da política monetária, uma vez que o efeito de um choque de juro sobre a produção industrial e a inflação após o controle para as condições financeiras, é praticamente nulo.

\section{Palavras-chave}

Condições Financeiras; FCI; FAVAR; VAR; Política Monetária. 


\section{Abstract}

Campos, Sarah Caroline Valcácio; Berriel, Tiago Couto (Advisor). The impact of financial conditions on the activity and its relevance in the transmission of monetary policy. Rio de Janeiro, 2020. 38p. Dissertação de Mestrado - Departamento de Economia , Pontifícia Universidade Católica do Rio de Janeiro.

The aim of this study is to analyze the effect of financial conditions on economic activity and to understand their role in the transmission of monetary policy. Our evidence suggests that, in the case of the United States, a tightening of financial conditions has an effect very similar to a contractionary interest rate shock. Despite this, when controlling the interest rate for the FCI, the results indicate that monetary policy innovations does not operate through financial conditions. Such a conclusion, however, can't be generalized to other countries. We find that, in the case of Canada, financial conditions are relevant to the transmission of monetary policy, since the effect of an interest rate shock on industrial production and inflation after controlling for financial conditions, is practically nil.

\section{Keywords}

Financial Conditions; FCI; FAVAR; VAR; Monetary Policy. 


\section{Sumário}

1 Introdução 11

2 Revisão de Literatura $\quad 13$

$\begin{array}{lll}3 & \text { Dados e Metodologia } & 17\end{array}$

3.1 Índice de Condições Financeiras (FCI) 17

$\begin{array}{ll}3.2 & 18\end{array}$

$\begin{array}{ll}3.3 \text { Modelagem VAR } & 19\end{array}$

4 Estimação e Resultados $\quad 21$

$\begin{array}{lll}4.1 & \text { Exercício para Outros Países } & 25\end{array}$

$\begin{array}{lll}5 & \text { Conclusão } & 27\end{array}$

A Índice de Condições Financeiras $\quad 31$

B Função Impulso-Resposta (IFR) 34 


\section{Lista de figuras}

Figura 4.1 Choque Contracionista de Condições Financeiras - com

PCE 21

Figura 4.2 Choque do Resíduo da Fed Funds Rate (FFR) - com PCE 22

Figura 4.3 Comparativo entre um choque da FFR (esquerda) e um choque da FFR controlada para as condições financeiras (direita) 23

Figura 4.4 Canadá: Comparativo entre um choque de juros (esquerda) e um choque de juros controlado para as condições financeiras (direita)

Figura A.1 Índice de Condições Financeiras - Estados Unidos 32

Figura A.2 Índice de Condições Financeiras - Canadá 33

Figura A.3 Índice de Condições Financeiras - Outros Países 33

Figura B.1 Choque de Política Monetária Contracionista - com PCE 34

Figura B.2 Choque de Política Monetária Contracionista - com CPI 35

Figura B.3 Choque Contracionista de Condições Financeiras - com $\mathrm{CPI}$

Figura B.4 Choque do Resíduo da Fed Funds Rate (FFR) - com PCE 36

Figura B.5 Choque do Resíduo da Fed Funds Rate (FFR) - com CPI 36

Figura B.6 Brasil: Comparativo entre um choque de juros (esquerda) e um choque de juros controlado para as condições financeiras (direita)

Figura B.7 África do Sul: Comparativo entre um choque de juros (esquerda) e um choque de juros controlado para as condições financeiras (direita) 


\section{Lista de tabelas}

Tabela A.1 FCI: Variáveis 


\section{Lista de Abreviaturas}

FCI - Financial Conditions Index

FAVAR - Factor-augmented vector autoregression

VAR - Vetores Autoregressivos

FED - Federal Reserve

FFR - Fed Funds Rate

PPI - Producer Price Index

PCE - Personal Consumption Expenditures

BoJ - Bank of Japan

$\mathrm{BoC}$ - Bank of Canada

IFR - Função Impulso-Resposta

BCE - Banco Central Europeu

OEC - Observatory of Economic Complexity

BCPI - Bank of Canada Commodity Price Index

KSFCI - Kansas City Financial Stress Index

NFCI - National Financial Conditions Index

FCI - Financial Conditions Index

FAVAR - Factor-augmented vector autoregression

VAR - Vetores Autoregressivos

FED - Federal Reserve

FFR - Fed Funds Rate

PPI - Producer Price Index

PCE - Personal Consumption Expenditures

BoJ - Bank of Japan

BoC - Bank of Canada

IFR - Função Impulso-Resposta

BCE - Banco Central Europeu

OEC - Observatory of Economic Complexity

BCPI - Bank of Canada Commodity Price Index

KSFCI - Kansas City Financial Stress Index

NFCI - National Financial Conditions Index 


\section{Introdução}

As condições financeiras afetam os planos de poupança e investimento de empresas e famílias e, portanto, é fácil perceber que estas exercem um papel fundamental sobre os ciclos econômicos. Estudos sobre a relação entre as condições financeiras e a economia real cresceram de forma significativa ao longo dos anos, em especial após a crise de 2008. William Dudley, em um discurso ${ }^{1}$ realizado em 2017, destacou a importância das condições financeiras na condução da política monetária americana. O ex-presidente do Fed de Nova York classificou o tema como "próximo e querido" ao seu coração. Embora nenhum banco central no mundo possua uma meta relacionada às condições financeiras, é comum observar em seus documentos oficiais trechos descritivos sobre a evolução destas, bem como a respeito do funcionamento dos mercados financeiros.

A motivação deste trabalho consiste em avaliar o efeito das condições financeiras sobre a atividade econômica e entender o papel destas na transmissão da política monetária. Em outras palavras, estamos interessados em responder as seguintes perguntas: i) Um aperto nas condições financeiras tem o mesmo efeito sobre a atividade e a inflação que um aumento de juros? e ii) Qual a relevância das condições financeiras no canal de transmissão da política monetária?

Para tanto, serão realizadas algumas etapas. A primeira consiste na construção de um índice de condições financeiras (FCI, na sigla em inglês) através do método de componentes principais. Na segunda etapa, estimaremos um modelo econométrico que nos permita explorar o impacto do FCI na atividade econômica e na inflação. Por fim, utilizaremos o mesmo modelo para calcular o efeito de um choque de juros livre das condições financeiras, isto é, controlado para o FCI.

Um índice de condições financeiras pode ser definido como uma forma de sintetizar a informação contida em diversas variáveis, facilitando o entendimento sobre o estado atual e futuro da economia. Como discutiremos mais à frente, existem diversas variáveis que podem ser levadas em conta. Um FCI

\footnotetext{
${ }^{1}$ William C Dudley: The importance of financial conditions in the conduct of monetary-
} policy. BIS, 2017. 
viabiliza, entre outros, uma melhor percepção quanto ao aumento da incerteza, tornando-se útil para captar momentos de estresse financeiro.

Nas etapas 2 e 3 descritas previamente, utilizaremos a modelagem de FAVAR (factor-augmented vector autoregression) realizada em Boivin, Giannoni e Mihov (2009) para responder as perguntas de interesse para os Estados Unidos. Uma das principais características de um FAVAR é fornecer estimativas de fatores que afetam os dados de interesse, permitindo a análise sistemática de todas as informações contidas em um grande conjunto de indicadores econômicos.

Em seguida, expandiremos a análise para outros países. Com intuito de facilitar o estudo, vamos utilizar um VAR simples, já que um FAVAR requer um número elevado de indicadores. A título de comparação, o FAVAR estimado pelos autores no paper supracitado utiliza mais de 650 séries de dados, enquanto em um VAR são utilizadas menos que uma dezena de variáveis.

Uma breve revisão de literatura sobre o tema das condições financeiras é feita na seção 2. A base de dados utilizada e a metodologia realizada em cada uma das etapas estão descritas na seção 3. Na seção 4, são apresentados os principais resultados e, finalmente, a conclusão é feita na seção 5 . 


\section{2}

\section{Revisão de Literatura}

Existem diversos trabalhos na literatura que buscam quantificar a evolução das condições financeiras e seus efeitos na atividade econômica. A bolha da internet, que estourou nos anos 2000, levantou a questão sobre o quanto os bancos centrais deveriam levar em consideração preços de ativos na tomada de decisão, mas o protagonismo dos índices de condições financeiras ganhou ainda mais força após a Grande Crise Financeira de 2008, em especial no que tange à condução de política monetária.

Em Hatzius et al. (2010), há uma vasta discussão das variáveis a serem incluídas, o método de construção e o poder preditivo de tais índices. A quantidade de variáveis pode variar de algumas até centenas, enquanto a frequência pode ser mensal, semanal ou até mesmo diária. Angelopoulou, Balfoussia e Gibson (2014) construíram um FCI para a Zona do Euro e para os países da união monetária individualmente através do método de componentes principais, utilizando uma ampla variedade de dados, tal como spreads, volume de crédito, volume de atividade no mercado de títulos de dívida, volatidade e outros. Essa investigação nos países de forma individual, para além da Zona do Euro, revelou resultados interessantes. Enquanto as condições financeiras na Grécia e em Portugal continuaram a se deteriorar no período pós crise, o FCI da Alemanha mostra as condições financeiras melhorando aos poucos, ou seja, caminhando para patamar acomodatício e revelando um importante desafio da política monetária dentro da região que permeia até hoje as discussões do Banco Central Europeu (BCE). O mesmo método foi utilizado em English, Tsatsaronis, Zoli et al. (2005) e Sandahl et al. (2011). No primeiro, os autores utilizam os componentes principais para extrair informação de um grande conjunto de variáveis consideradas potencialmente importantes para realizar previsões de produto, inflação e investimento. O exercício foi conduzido para os EUA, Reino Unido e Alemanha. Os resultados indicam que os "fatores financeiros" obtidos pelo método descrito acima são bons na previsão de produto e investimento. Por outro lado, o resultado não é tão satisfatório quando se trata de projeção da inflação. No segundo, os autores constroem um índice de estresse financeiro para a Suécia com objetivo de analisar desenvolvimentos no mercado financeiro, concluindo que o índice 
pode fornecer indicações de estresse, mas que mudanças no índice também podem ocorrer por outros motivos. Outros métodos incluem uma média simples das variáveis incluídas, como no Bloomberg FCI ou o emprego das variáveis ponderadas pelo impacto estimado no PIB ou inflação, como feito em Swiston (2008). Swiston (2008) defende a inclusão da disponibilidade de crédito entre as variáveis como sendo de excepcional importância, já que esta é altamente prócíclica. Segundo o autor, o impacto da política monetária não é corretamente identificado quando a disponibilidade de crédito não é incorporada ao modelo, o que dá sustentação à existência do canal de crédito da política monetária.

Diversos trabalhos foram produzidos destacando a utilidade de FCIs para previsão econômica e períodos de estresse financeiro. Koop e Korobilis (2014) utilizam o método de FAVAR com coeficientes variáveis no tempo para estimar um FCI para os EUA. O peso de uma variável no FCI pode ser até mesmo zero, quando esta não for selecionada. Os autores defendem que, desta forma, a modelagem leva em consideração a natureza distinta das crises financeiras e de como estas são transmitidas à economia real. Os resultados indicam poder preditivo para crescimento do PIB, inflação e desemprego. Brave, Butters et al. (2012) mostram que o NFCI (National Financial Conditions Index) produzido pelo FED de Chicago é um indicador antecedente robusto para estresse financeiro no horizonte de até um ano. Além disso, a divisão do NFCI em subcomponentes de risco, crédito e alavancagem fornecem uma boa indicação quanto à severidade da crise. Em contrapartida, para períodos superiores a um ano, os autores evidenciam que uma combinação de medidas de alavancagem das famílias e de empresas não-financeiras são indicadores de estrese financeiro.

Hakkio, Keeton et al. (2009) destacaram a redução da disposição à aquisição de ativos arriscados ou ilíquidos - movimentos conhecidos como flight to quality e flight to liquidity, entre as principais características de um estresse financeiro. Os autores controem o KSFCI (Kansas City Financial Stress Index) através da combinação de 11 variáveis financeiras, explicitando como o índice foi capaz de reconhecer períodos de estresse financeiro na amostra compreendida entre 1990 e 2009. Além disso, o KSFCI também se mostrou eficaz em antecipar mudanças na atividade econômica. Uma conclusão bastante interessante do paper baseia-se em como o índice pode ser útil para o FED em sua estratégia de política monetária, em especial na decisão de retirar liquidez após uma crise, uma vez que a autoridade monetária pode observar se o estágio das condições financeiras não mais apontam uma ameaça para a atividade econômica à frente.

Bernanke e Gertler (1995) destacaram como fricções no mercado finan- 
ceiro podem afetar o canal de transmissão da política monetária, enquanto Zeldes (1989) documentou o efeito de restrições de liquidez no consumo das famílias. Ainda neste campo de estudo, preços de ativos e as condições financeiras de uma forma geral podem exercer papel importante na transmissão da política monetária através do efeito renda e/ou do canal de crédito. Em trabalhos mais recentes, como Montagnoli and Napolitano (2004) Napolitano e Montagnoli (2004), os autores investigam o papel dos preços de ativos na condução da política monetária, construindo uma regra de Taylor aumentada para incluir o FCI. Os resultados sugerem que o FCI entra positiva e estatisticamente significante na definição de juros pelo FED, sinalizando favoravelmente quanto ao uso deste indicador na condução da política monetária.

Dudley (2017) Dudley (2017) argumenta que as condições financeiras nos Estados Unidos desempenham um papel relevante sobre as condições econômicas. Por exemplo, um aumento dos preços das ações pode causar um efeito renda positivo, aumentando o consumo. O valor do dólar pode afetar a competitividade relativa de exportadores e importadores, influenciando o desempenho comercial do país. Menores spreads de crédito podem reduzir o custo do capital, ajudando a sustentar o investimento, entre outros. De acordo com Dudley, as condições financeiras nos Estados Unidos podem ser sumarizadas por cinco indicadores principais: taxa de juros de curto e longo prazo, spread de crédito, dólar e o preço das ações, variáveis usadas neste trabalho para estimação do FCI. Ele argumenta que se as condições financeiras se movessem de forma previsível mediante mudanças na taxa de juros, não haveria necessidade do banco central se concentrar nas condições financeiras. Entretanto, a resposta das condições financeiras não é rígida e previsível. Além disso, já houve episódios em que as condições financeiras e a taxa de juros se moveram em direções opostas. Há diversas razões pelas quais essa relação pode variar, como animal spirits nos mercados financeiros, condições externas e estresse/instabilidade financeira, causando aumento da aversão ao risco. Dudley ressalta que divergências entre as taxas de juros de curto prazo e as condições financeiras parecem maiores e mais persistentes nos EUA do que na maioria dos países desenvolvidos. Algumas possíveis explicações para isso estão ligadas a menor dependência do sistema bancário na intermediação de fluxos financeiros, a taxa de hipoteca não acompanhar o juro de curto prazo e a importância do mercado acionário em comparação com outras regiões. Nossas estimativas de que choques de condições financeiras possuem efeito bastante similar a um choque de política monetária sobre atividade e inflação vão em linha com a argumentação por parte do ex-presidente do FED de NY de que as condições financeiras precisam ser cuidadosamente acompanhadas na condução 
de política monetária. Neste sentido, Dudley ainda destaca a necessidade de cautela ao seguir a regra de Taylor, já que esta não leva em consideração as condições financeiras, podendo ser um preditor ruim para a definição da taxa de juros. 


\section{3 \\ Dados e Metodologia}

\section{1}

\section{Índice de Condições Financeiras (FCI)}

Para a construção dos índices de condições financeiras (FCIs), optamos pelo método de componentes principais. Este método é uma ferramenta capaz de converter um grande número de variáveis em um número pequeno, mas preservando a maior parte da informação contida no conjunto inicial de dados.

Tal como destacado na revisão de literatura, existem diversas maneiras de calcular um FCI. Entre elas, o método supracitado é comumente utilizado, uma vez que o processo matemático é bastante simples. Definimos, portanto, o FCI como o primeiro componente principal extraído das variáveis selecionadas para cada país, já que neste componente está contido o maior percentual possível da variância dos dados.

Na construção do FCI, são utilizados dados mensais das seguintes variáveis: taxa de juros - curta e longa, uma medida de spread, taxa de câmbio e índice de preço de ações. Estas cinco variáveis, em nossa visão, são suficientes para realizar um bom prognóstico acerca das condições financeiras de um país. De forma mais específica, para os Estados Unidos, estamos falando da Fed Funds Rate - taxa de juros definida pelo FED (banco central americano), o juro do título público de 10 anos, o spread corporativo em relação ao título de 10 anos, o DXY e o índice S\&P 500.

A série para os EUA contém dados desde janeiro/1976 até dezembro/2007, ou seja, até o período pré-crise.

No exercício de extensão para outros países, algumas variáveis foram incluídas na estimação do FCI, com objetivo de melhor capturar características intrínsecas à cada região. Neste sentido, enquanto para os países desenvolvidos - EUA, Alemanha, França, Itália, Canadá, Japão e Reino Unido - são utilizados dados de corporate spread, para os países emergentes - Brasil, África do Sul, Chile e Rússia -, o CDS foi escolhido como medida de risco. Para a França e a Itália, também foi acrescentado o spread do juros de 10 anos de cada um em relação ao título alemão de 10 anos. Este último, denominado como government spread. Finalmente, para o Canadá e o Chile, além das variáveis 
já citadas, os FCIs incluem um índice de preços de commodities e o preço do cobre, respectivamente.

Retiramos a tendência contida nos índices de ações, nas moedas e nos preços de commodities. As variáveis foram transformadas para garantir que um aperto das condições financeiras significasse uma elevação do nosso índice. Todas as variáveis foram normalizadas. Uma tabela mais detalhada dos dados encontra-se no apêndice. A série para todos os demais países vai de junho/2003 até dezembro/2019.

\section{2 \\ Modelagem FAVAR}

A estrutura empírica que consideramos respalda-se no modelo de FAVAR descrito por Boivin, Giannoni e Mihov (2009). Os autores exploram a informação contida em um grande número de indicadores macroeconômicos, incluindo diversas medidas de produção industrial, índices de preços, taxa de juros, emprego e outros - tal como feito em Bernanke, Boivin e Eliasz (2005) -, além de dados desagregados do PPI (producer price index) e de preços e consumo do PCE (personal consumption expenditures).

Ao todo, são utilizadas 653 séries mensais, para o período de 1976:1 a 2005:6. Os dados e as transformações aplicadas a cada série em particular, estão indicados e foram retirados do apêndice publicado na página da American Economic Association Boivin, Giannoni e Mihov 2019.

Como defendido por Bernanke, Boivin e Eliasz (2005), essa estrutura pode levar à uma melhor identificação do choque de política monetária em comparação à modelagem padrão de VAR, uma vez que reconhece o grande conjunto de informações que os bancos centrais e os participantes do mercado financeiro possuem.

Tal como apresentado pelos autores, assumimos que a economia é afetada por um vetor $\mathrm{C}_{t}$ de componentes comuns a todas as variáveis que entram no conjunto de dados. Como estamos interessados em caracterizar os efeitos de um choque de juros, esse vetor de componentes comuns inclui uma medida de postura/orientação da política monetária. Nos Estados Unidos, define-se o instrumento de política monetária como a fed funds rate, $\mathrm{R}_{t}$. Note que é permitido que a taxa de juros tenha efeito difundido em toda a economia e, portanto, será considerada como um componente comum de todas as variáveis que entram no conjunto de dados.

Vamos assumir que toda informação adicional à taxa de juros possa ser sumarizada por um vetor $\mathrm{K} \times 1$ de fatores não observáveis $\mathrm{F}_{t}$, onde $\mathrm{K}$ é relativamente pequeno. Esses fatores podem ser entendidos como condições econô- 
micas gerais, capturados por uma ampla gama de variáveis. Logo, assumimos que a dinâmica entre $\mathrm{F}_{t}$ e $\mathrm{R}_{t}$ é dada por

$$
\mathbf{C}_{t}=\boldsymbol{\Phi}(L) \mathbf{C}_{t-1}+\mathbf{v}_{t}
$$

onde

$$
\mathbf{C}_{t}=\left[\begin{array}{c}
\mathbf{F}_{t} \\
R_{t}
\end{array}\right],
$$

e $\phi(L)$ é um polimônio autorregressivo de ordem finita. O termo de erro $\mathrm{v}_{t}$ é i.i.d. com média zero.

Seja $\mathrm{X}_{t}$ o vetor $\mathrm{N}$ x 1 de variáveis informacionais em que $\mathrm{N}$ é considerado grande, ou seja, $\mathrm{N} \gg \mathrm{K} \times 1$, assumimos que o grande conjunto de séries de $\mathrm{Xt}$ está relacionado aos fatores comuns de acordo com

$$
\mathbf{X}_{t}=\Lambda \mathbf{C}_{t}+\mathbf{e}_{t}
$$

onde $\Lambda$ é uma matriz $\mathrm{N}$ x $(\mathrm{K}+1)$ de cargas fatoriais e o vetor $\mathrm{N} \times 1 \mathrm{e}_{t}$ contém componentes específicos de séries que não são correlacionados com os componentes comuns $\mathrm{C}_{t}$.

O modelo é então estimado através de uma abordagem em duas etapas. Na primeira etapa, extraímos os componentes principais do grande conjunto de dados em $\mathrm{X}_{t}$ para obter estimativas consistentes dos fatores comuns. $\mathrm{Na}$ segunda etapa, adicionamos a fed funds rate aos fatores estimados e estimamos o VAR estrutural em (3-1).

\section{3 \\ Modelagem VAR}

Na seção anterior, descrevemos a modelagem FAVAR que será utilizada em nossa estimação principal, para os Estados Unidos. No entanto, como iremos expandir a análise para um grupo de países e a principal característica do FAVAR é seu grande número de variáveis, tornou-se necessário migrar para um modelo em que fosse exigido apenas um pequeno número de indicadores.

Em Boivin, Giannoni e Mihov (2009), além da abordagem FAVAR, foram estimados choques de política monetária para um VAR padrão simples, contendo produção industrial, inflação e taxa de juros. Desta forma, fez-se apropriado a utilização do mesmo modelo em nosso exercício, com objetivo de tornar comparável as estimações realizadas.

Ao longo dos anos, desenvolveu-se uma vasta literatura que emprega modelos autorregressivos para tentar identificar e medir os efeitos de inovações de política econômica. A abordagem VAR, embora não lhe faltem críticas, parece 
fornecer uma quantidade satisfatória de avaliações estruturais, especialmente para um método tão simples.

É bastante comum encontrarmos, por exemplo, o chamado "price puzzle", isto é, um aumento da inflação mediante um choque contracionista não antecipado da taxa de juros, nas estimações de modelos VAR. De acordo com Sims (1992), isto estaria associado ao controle imperfeito da informação que um banco central possui em relação à inflação futura. Em outras palavras, os dados incluídos no modelo não estariam capturando a expectativa que o banco central possui de que a inflação vá subir à frente quando este decide elevar o juro.

Apesar disso, acreditamos que o modelo é capaz de nos fornecer uma quantidade útil de informações e realizar as inferências necessárias para responder as perguntas de interesse do presente estudo.

Em relação à base de dados propriamente dita, as séries de produção industrial e de índices de preços, dessazonalizadas, foram transformadas através da primeira diferença do logaritmo com objetivo de induzir estacionariedade. Para os países emergentes, para o Canadá e o Reino Unido, a amostra compreende o período entre 2003:7 e 2019:12. No entanto, para os EUA e os países da Europa, a amostra termina em 2007:12, antes da crise financeira. Para o Japão, a amostra se estende até 2015:12, ja que, em 2016, o BoJ (banco central do Japão) adotou taxa de juros negativa. A série de taxa de juros de cada um dos países (\% ano) não sofreu transformações. 


\section{4}

\section{Estimação e Resultados}

Para responder a primeira pergunta de interesse, calculamos a resposta da produção industrial e da inflação a um choque contracionista das condições financeiras, ou seja, um aumento do FCI. Como vemos na figura 4.1 abaixo, a resposta da produção industrial vai em linha com o esperado à luz da teoria econômica: mediante um choque contracionista das condições financeiras, há um recuo da produção industrial. No entanto, em comparação com um choque de taxa de juros na mesma direção, o efeito máximo se dá alguns meses depois. A resposta do PCE também vai na direção esperada a priori, embora seu efeito máximo, em nível, seja superior ao da fed funds rate. As funções impulsoresposta para um choque de política monetária encontram-se no apêndice. Os modelos foram estimados para o PCE e para o CPI.
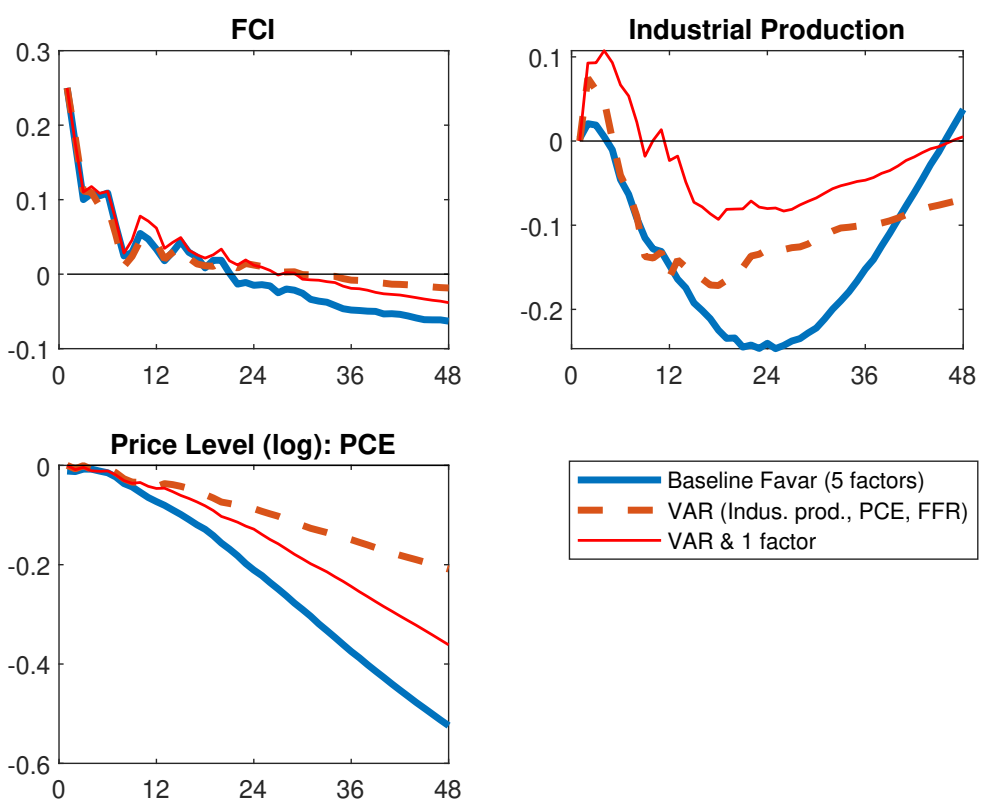

Figura 4.1: Choque Contracionista de Condições Financeiras - com PCE

Um resultado positivo das nossas estimações com o modelo principal, descrito no gráfico como "Baseline Favar" é de que não constatamos a presença de price puzzle, independente do índice de preços utilizado. Deste modo, embora as IFRs calculadas não sejam exatamente idênticas, podemos dizer 
que o efeito das condições financeiras sobre a atividade econômica é bastante similar a um aperto de juros.

Após a análise de um choque de condições financeiras sobre a atividade nos Estados Unidos, o segundo momento centrou-se em entender se o efeito da taxa de juros nas variáveis econômicas passa pelas condições financeiras. Para tal propósito, estimamos um VAR simples da taxa de juros e do FCI. Em seguida, utilizamos a taxa de juros "limpa" do FCI, ou seja, controlada para esta variável, para estimar novamente o FAVAR. Note que o objetivo aqui, ao substituir a Fed Funds pelo seu resíduo, é verificar se os resultados iniciais são alterados. Em outras palavras, se mesmo após controlar para o FCI, o resultado é o mesmo, isto significa que tal variável não possui relevância no canal de transmissão do choque de política monetária.

O cálculo da IFR para o exercício acima, está sumarizado na figura 4.2. Verificamos, portanto, que a resposta da atividade econômica neste caso é bastante similar ao choque da taxa de juros sem realizarmos qualquer controle para o FCI. Nossos resultados sugerem que, embora, as condições financeiras tenham impacto sobre a atividade e a inflação, o choque de política monetária atua, pelo menos majoritariamente, per se. Para validar este resultado, estimamos um VAR estrutural com produção industrial e inflação e estendemos a amostra para até 2007:12.
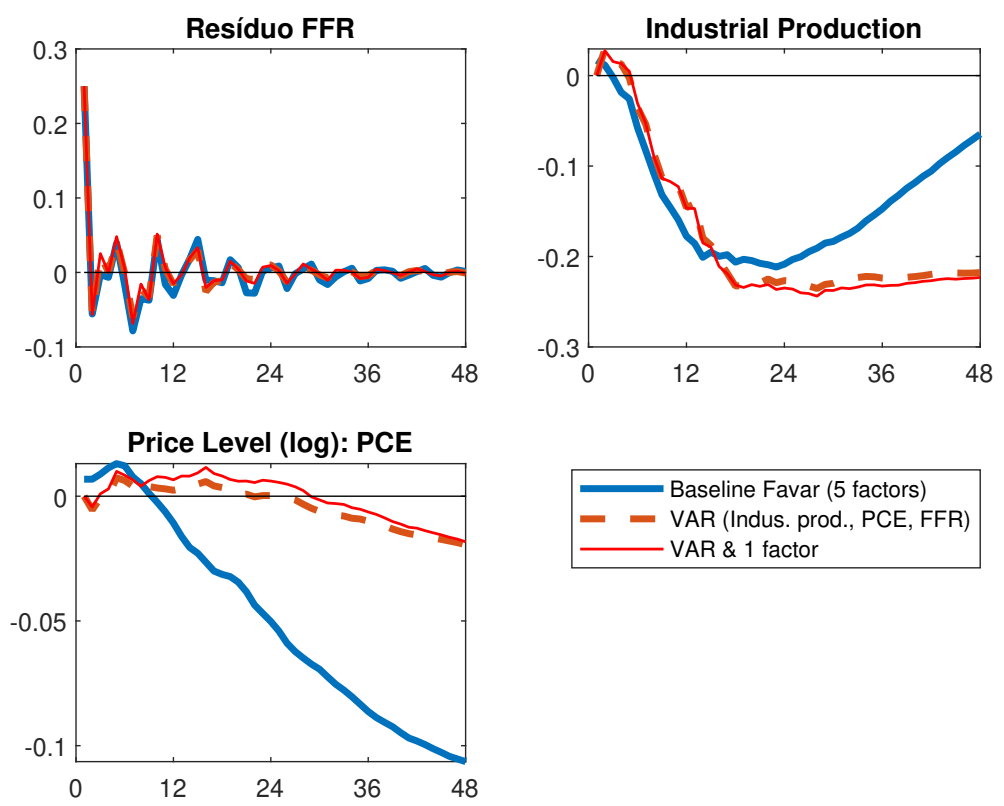

Figura 4.2: Choque do Resíduo da Fed Funds Rate (FFR) - com PCE

Os resultados do VAR são bastante similares ao encontrado em nossa estimativa principal. À esquerda da figura 4.3, temos o efeito de um choque da 
taxa de juros sobre a produção industrial e o PCE, enquanto, à direita, temos o efeito do juro já controlado para as condições financeiras sobre as mesmas variáveis. Novamente, não encontramos evidência de que inovações de política monetária atuam através das condições financeiras.
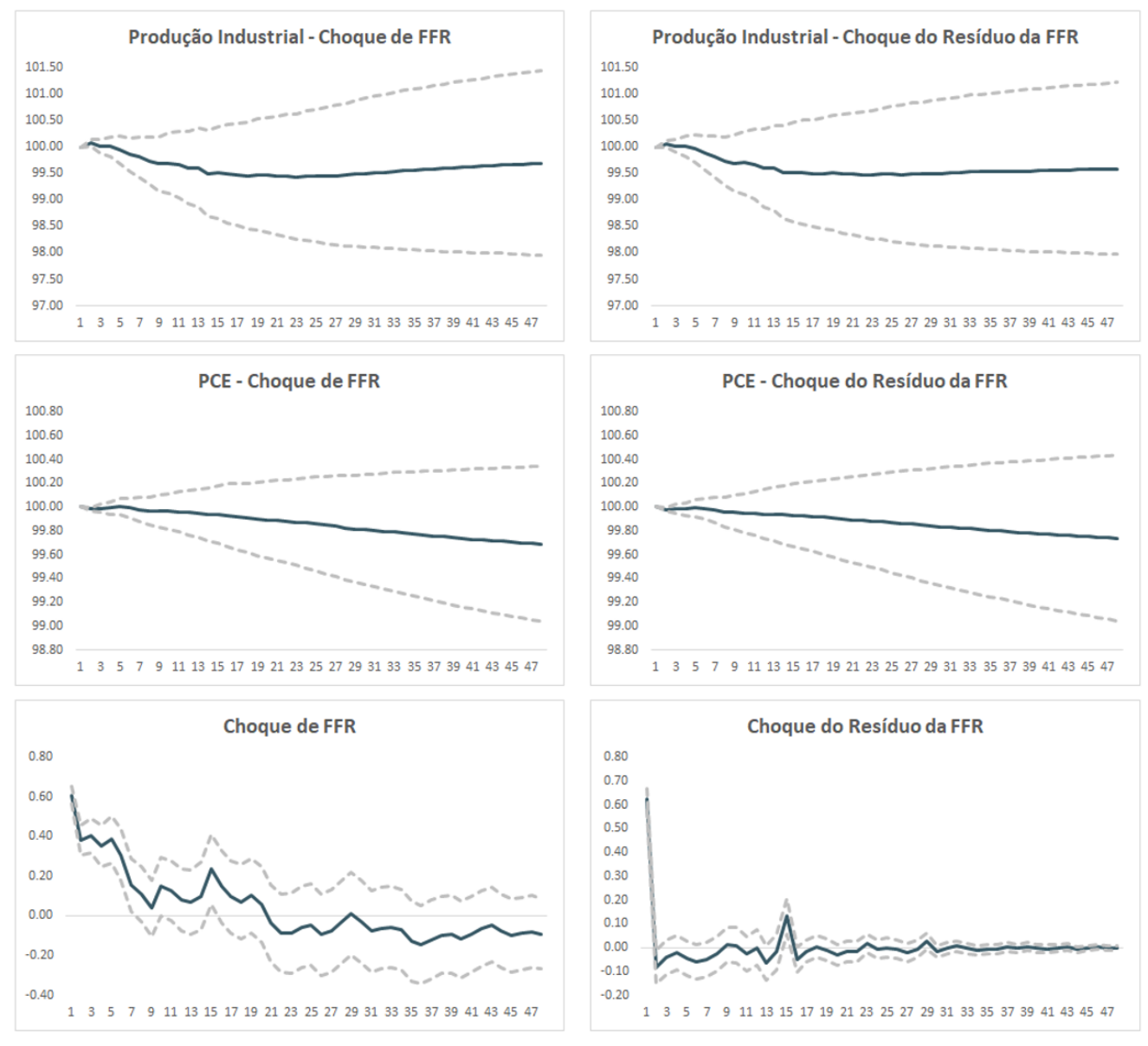

Figura 4.3: Comparativo entre um choque da FFR (esquerda) e um choque da FFR controlada para as condições financeiras (direita)

Enquanto, para os Estados Unidos, um choque de política monetária parece atuar de forma independente, as mesmas conclusões não são verificadas para o Canadá. Realizamos, para a economia canadense, o mesmo exercício descrito para os EUA, estimando um VAR para a amostra compreendida entre 2003:7 e 2019:12. Nossas estimativas mostram que um choque contracionista de juros reduz, como esperado, a produção industrial. O efeito sobre a inflação é mais incerto. Cabe destacar, como já apontado na metodologia, que modelos VAR possuem limitações, como seu pequeno número de variáveis explicativas, podendo este ser um dos motivos pelo qual não identificamos o efeito esperado a priori para a inflação.

Não obstante à ressalva feita, verificou-se um interessante resultado nas estimativas: um choque de taxa de juros, controlado para as condições finan- 
ceiras, possui efeito praticamente nulo sobre a produção industrial e a inflação no Canadá (figura 4.4). Isto significa dizer que as condições financeiras, aqui representadas pelo nosso FCI, desempenham papel relevante na transmissão de inovações de política monetária para a economia canadense.

Algumas possíveis explicações podem estar por trás do resultado encontrado para os dois países. Em primeiro lugar, o Canadá pode ser classificado como uma pequena economia aberta. Em economias como esta, o mercado externo desempenha um papel relevante nas condições - econômicas e financeiras - domésticas, enquanto, o contrário, não é valido. No caso do Canadá, estamos falando de um país especialmente ligado aos Estados Unidos. De acordo com dados do OEC (Observatory of Economic Complexity) ${ }^{1}$, mais de $70 \%$ das exportações do Canadá tem como destino os Estados Unidos. Já no lado das importações, mais de $45 \%$, tem como origem o país norte-americano. Isto torna os Estados Unidos, de longe, o principal parceiro comercial do Canadá. Portanto, tudo mais constante, um crescimento menor nos EUA, diminui a demanda por produtos importados, refletindo-se em uma queda das exportações do Canadá.

As características acima descritas nos permitem inferir que outras variáveis, além da taxa de juros doméstica, são importantes para a evolução da economia canadense. Essas outras variáveis, como a variação do câmbio, por exemplo, são captadas pelo FCI. Ainda na questão comercial, nosso FCI para o Canadá também inclui o Bank of Canada commodity price index (BCPI). De acordo com o próprio BoC (banco central do Canadá), "uma vez que os preços das commodities produzidas no país têm implicações importantes para o desempenho da economia canadense, a interpretação dos desenvolvimentos nos mercados de commodities é crítica para a condução da política monetária e uma medida precisa dos movimentos gerais dos preços é essencial". O BCPI inclui preços de energéticos, como o petróleo, metais, minérios, agrícolas, entre outros.

Uma outra explicação possível para a diferença entre os resultados provém do sistema bancário nos dois países. A concentração bancária nos EUA, por exemplo, é quase metade da observada no Canadá, de acordo com dados disponíveis no site do Banco Mundial. Embora uma análise mais aprofundada sobre o sistema bancário nos dois países fugisse do escopo do presente trabalho, estudos sugerem que, em mercados mais competitivos, a efetividade da política monetária é maior. Severe (2016) investiga como a concentração bancária afeta a transmissão da política monetária através do efeito de uma mudança nos juros sobre o valor agregado do setor manufatureiro. Os dados consistem em

\footnotetext{
${ }^{1}$ Ver: https://oec.world/en/profile/country/can/
} 
um painel de 22 países da OCDE para o período de 1993 a 2005. O autor encontra que um afrouxamento monetário, ou seja, uma redução de juros, tem um efeito significativamente maior no crescimento em países com menor concentração bancária. Desta forma, isto nos levaria a concluir que, como os Estados Unidos possuem um sistema bancário mais competitivo, com menores restrições para a transmissão da política monetária, o juro é a variável mais relevante, capaz de agir de forma independente sobre a atividade e a inflação.
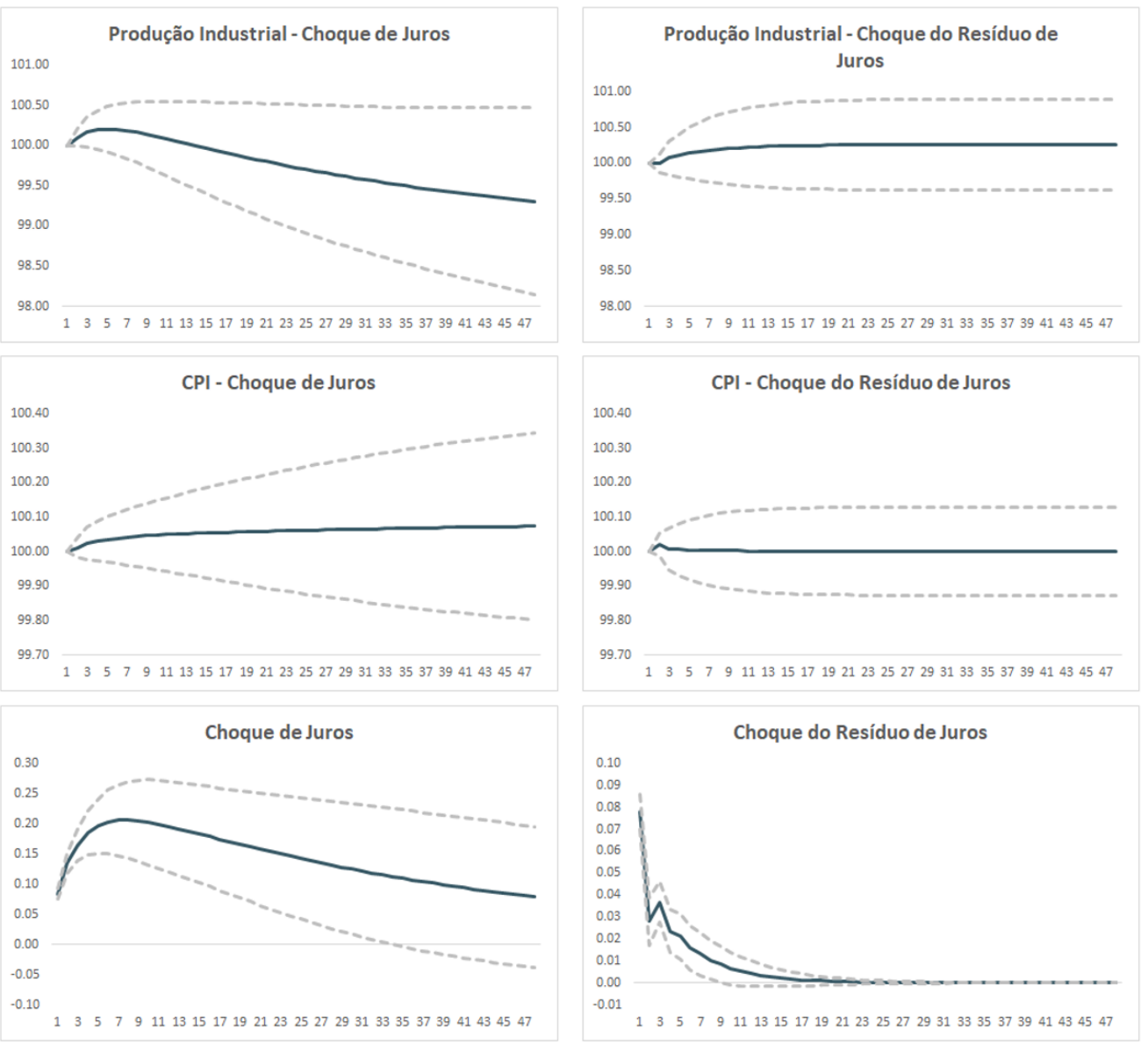

Figura 4.4: Canadá: Comparativo entre um choque de juros (esquerda) e um choque de juros controlado para as condições financeiras (direita)

\section{1}

\section{Exercício para Outros Países}

Realizamos os exercícios e estimações descritos nas seções anteriores para outros países, além de Estados Unidos e Canadá, tais sejam: Alemanha, França, Itália, Japão, Reino Unido, Brasil, África do Sul, Chile e Rússia. Os resultados, no entanto, não nos pareceram conclusivos e qualquer inferência poderia estar incorreta. 
Para melhor explanação, em diversos países, a resposta da inflação mediante um choque contracionista de juros ou de condições financeiras era contra-intuitivo, ou seja, as funções impulso-resposta do VAR indicavam uma alta da inflação nos períodos subsequentes. Em outros casos, como a Alemanha, por exemplo, o modelo indicava uma resposta contraditória com à teoria econômica também para a produção industrial.

Algumas possíveis explicações podem estar por trás dos resultados. Uma delas consiste na base de dados utilizada. Os dados escolhidos podem não refletir toda a informação necessária e estarmos cometendo algum tipo de omissão relevante para estimação. Além disso, os dados usados para estimação do FCI, como câmbio, podem apresentar alta volatidade para os países e períodos em questão e, portanto, não serem um bom indicativo das condições financeiras. O índice de condições financeiras do Chile, por exemplo, mostra-se bastante volátil, com alguns episódios de queda bastante notórios. Todos os FCIs estão disponíveis no apêndice.

Outra possível limitação está relacionada aos períodos amostrais. Para o Japão, a amostra se encerra em 2015, antes do país asiático adotar juro negativo. Para os países da Zona do Euro, os modelos auto-regressivos estimados tiveram a amostra encurtada para o período pré-crise. Para além de todas as deficiências relacionadas aos dados, a modelagem VAR também pode não ser a mais adequada para a estimação dos modelos dentro da amostra de países e períodos aqui determinados, considerando suas limitações já discutidas.

Elucidando os pontos expostos, as funções impulso- resposta para o Brasil e África do Sul foram incluídos no apêndice. Embora acreditemos que poucas implicações possam ser extraídas, suas inclusões tornam mais claras as questões deixadas em aberto. Analisemos, em ambos os casos, a resposta das variáveis a um choque de juros já controlado para as condições financeiras. Diferentemente dos Estados Unidos, onde encontramos IFRs bastante parecidas com o choque de juros puro, isto é, sem controle para as condições financeiras, ou do Canadá, onde a resposta da produção industrial e da inflação foram nulas mediante o choque, a resposta das variáveis são pouco conclusivas, isto porque temos um amplo intervalo de confiança, o que nos impede de compreender com segurança as direções tomadas por tais variáveis e, por consequência, nos impossibilita de responder as perguntas de interesse do presente trabalho. 


\section{5}

\section{Conclusão}

Através de uma modelagem FAVAR, que nos permite levar em consideração um grande conjunto de variáveis, fomos capazes de responder as duas perguntas de interesse propostas na introdução: i) Um aperto nas condições financeiras tem o mesmo efeito sobre a atividade e a inflação que um aumento de juros? e ii) Qual a relevância das condições financeiras no canal de transmissão da política monetária?

As evidências encontradas sugerem que, nos Estados Unidos, um aperto nas condições financeiras age de forma bastante similar a uma elevação nos juros. Ou seja, mediante um choque contracionista no FCI, a produção industrial e a inflação recuam nos períodos subsequentes ao choque.

Após controlarmos a fed funds rate para o FCI, com objetivo de responder a segunda pergunta, encontramos que o efeito de um choque no juro sobre a atividade econômica é praticamente idêntico ao efeito de um choque monetário sem qualquer controle para as condições financeiras. Este resultado, portanto, nos leva a concluir que inovações de política monetária nos EUA atuam per se, ou seja, de forma independente às condições financeiras.

Os resultados descritos nos parágrafos anteriores para os Estados Unidos, no entanto, não podem ser generalizados. Após a extensão da nossa análise para outros países, descobrimos que, diferentemente do caso americano, no Canadá, as evidências apontam para a importância de outras variáveis na transmissão da política monetária.

Mais precisamente, nossas estimativas mostram que a taxa de juros, controlada pelas condições financeiras, possui efeito praticamente nulo sobre a produção industrial e a inflação, o que significa dizer que as condições financeiras, aqui representadas pelo nosso FCI, desempenham papel relevante na transmissão da política monetária.

Algumas possíveis explicações podem estar por trás da diferença encontrada entre os dois países. Em primeiro lugar, o Canadá pode ser classificado como uma pequena economia aberta. Em economias como esta, o mercado externo possui grande relevância na conjuntura doméstica. No caso do Canadá, estamos falando de um país especialmente dependente dos Estados Unidos, seu principal parceiro comercial. Como mais de $70 \%$ das exportações do Canadá 
têm como destino os Estados Unidos, tudo mais constante, um crescimento menor nos EUA, diminui a demanda por produtos importados, levando a um menor crescimento do PIB canadense.

As características acima descritas nos permitem inferir que outras variáveis, além da taxa de juros doméstica, são importantes para a evolução da economia canadense. Nosso FCI captaria justamente essas outras variáveis, através da inclusão do câmbio e do BCPI (Bank of Canada commodity price index), por exemplo. De acordo com o próprio BoC (Banco Central do Canadá), "uma vez que os preços das commodities produzidas no país têm implicações importantes para o desempenho da economia canadense, a interpretação dos desenvolvimentos nos mercados de commodities é crítica para a condução da política monetária e uma medida precisa dos movimentos gerais dos preços é essencial".

Uma outra explicação possível estaria atrelada ao sistema bancário desses países. Severe (2016) investiga como a concentração bancária afeta a transmissão da política monetária através do efeito de uma mudança nos juros sobre o valor agregado do setor manufatureiro. O autor encontra que um afrouxamento monetário, ou seja, uma redução de juros, tem um efeito significativamente maior no crescimento em países com menor concentração bancária. Isto nos levaria a crer, portanto, que como os Estados Unidos possuem um sistema bancário mais competitivo, com menores restrições para a política monetária, o juro é a variável mais importante, capaz de agir de forma independente. No entanto, entendemos que tal conclusão depende de uma análise mais aprofundada do sistema bancário e de crédito nos dois países, o que pode ser objeto de estudo para outros trabalhos, mas fugia do escopo do presente estudo. 


\section{Bibliografia}

[1] Eleni Angelopoulou, Hiona Balfoussia e Heather D Gibson. "Building a financial conditions index for the euro area and selected euro area countries: what does it tell us about the crisis?" Em: Economic Modelling 38 (2014), pp. 392-403.

[2] Ben S Bernanke, Jean Boivin e Piotr Eliasz. "Measuring the effects of monetary policy: a factor-augmented vector autoregressive (FAVAR) approach". Em: The Quarterly journal of economics 120.1 (2005), pp. 387422.

[3] Ben S Bernanke e Mark Gertler. "Inside the black box: the credit channel of monetary policy transmission". Em: Journal of Economic perspectives 9.4 (1995), pp. 27-48.

[4] Jean Boivin, Marc P Giannoni e Ilian Mihov. "Replication data for: Sticky Prices and Monetary Policy: Evidence from Disaggregated US Data". Em: (2019).

[5] Jean Boivin, Marc P Giannoni e Ilian Mihov. "Sticky prices and monetary policy: Evidence from disaggregated US data". Em: American economic review 99.1 (2009), pp. 350-84.

[6] Scott Brave, R Andrew Butters et al. Diagnosing the financial system: financial conditions and financial stress. BiblioGov, 2012.

[7] William Dudley. The importance of financial conditions in the conduct of monetary policy: remarks at the University of South Florida SarasotaManatee, Sarasota, Florida. Rel. técn. Federal Reserve Bank of New York, 2017.

[8] William English, Kostas Tsatsaronis, Edda Zoli et al. "Assessing the predictive power of measures of financial conditions for macroeconomic variables". Em: BIS Papers 22 (2005), pp. 228-252.

[9] Craig S Hakkio, William R Keeton et al. "Financial stress: what is it, how can it be measured, and why does it matter?" Em: Economic Review 94.2 (2009), pp. 5-50.

[10] Jan Hatzius et al. Financial conditions indexes: A fresh look after the financial crisis. Rel. técn. National Bureau of Economic Research, 2010. 
[11] Gary Koop e Dimitris Korobilis. "A new index of financial conditions". Em: European Economic Review 71 (2014), pp. 101-116.

[12] A Napolitano e O Montagnoli. Financial Condition Index and interest rate settings: a comparative analysis. Rel. técn. Working Paper, 2004.

[13] Johannes Forss Sandahl et al. "An index of financial stress for Sweden". Em: $S$ v ER ig ESR ik S bank (2011), p. 2.

[14] Sean Severe. "An empirical analysis of bank concentration and monetary policy effectiveness". Em: Journal of Financial Economic Policy (2016).

[15] Christopher A Sims. "Interpreting the macroeconomic time series facts: The effects of monetary policy". Em: European economic review 36.5 (1992), pp. 975-1000.

[16] Andrew Swiston. A US financial conditions index: putting credit where credit is due. 8-161. International Monetary Fund, 2008.

[17] Stephen P Zeldes. "Consumption and liquidity constraints: an empirical investigation". Em: Journal of political economy 97.2 (1989), pp. 305346. 


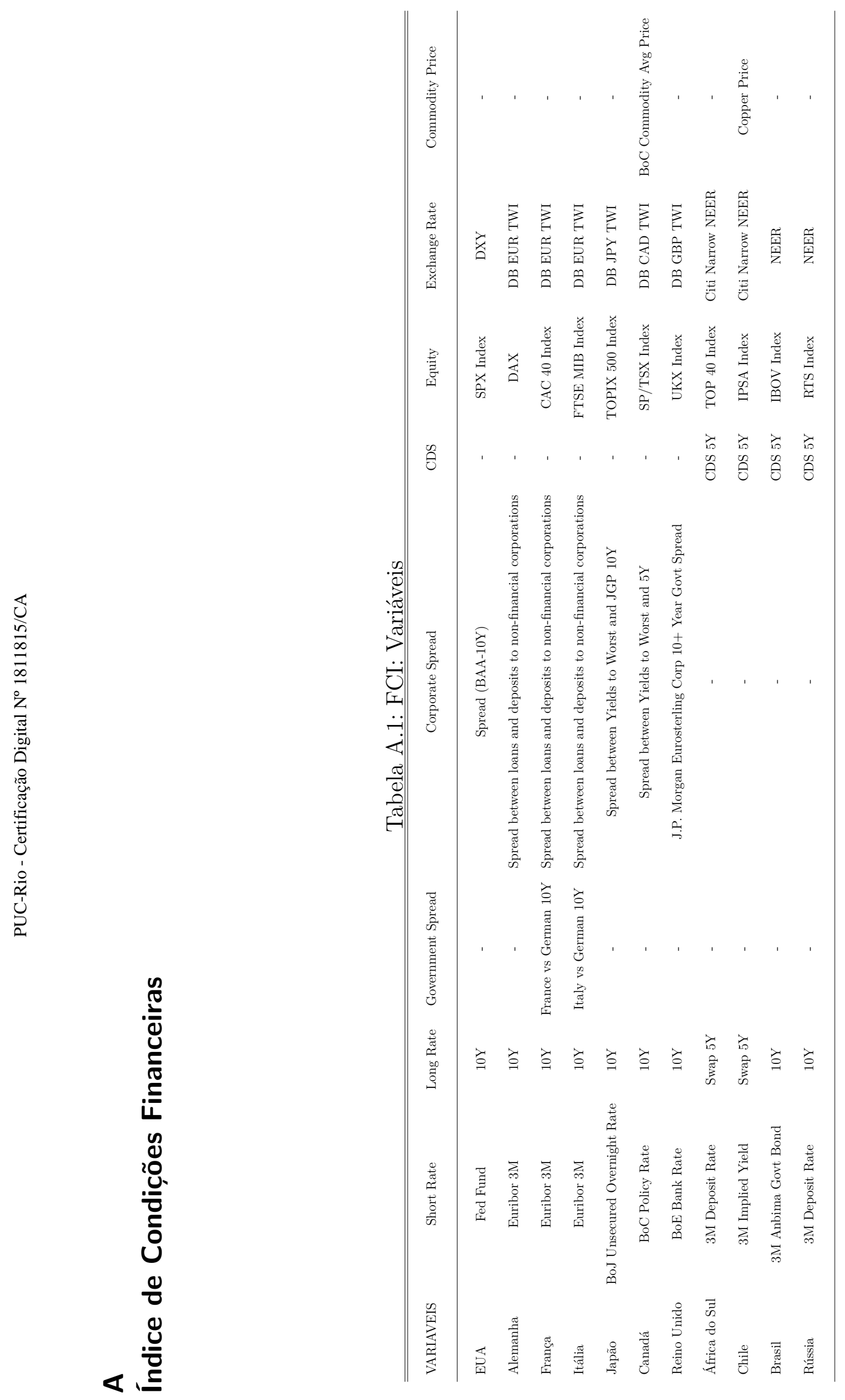


EUA - FCl

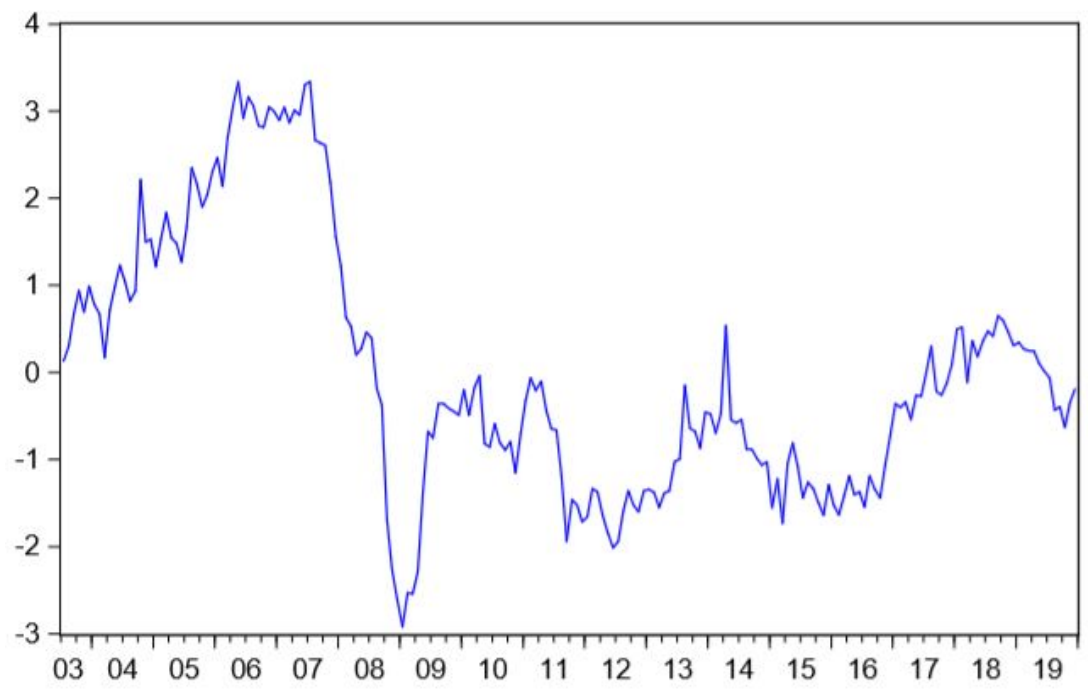

Figura A.1: Índice de Condições Financeiras - Estados Unidos 
Canadá - $\mathrm{FCl}$

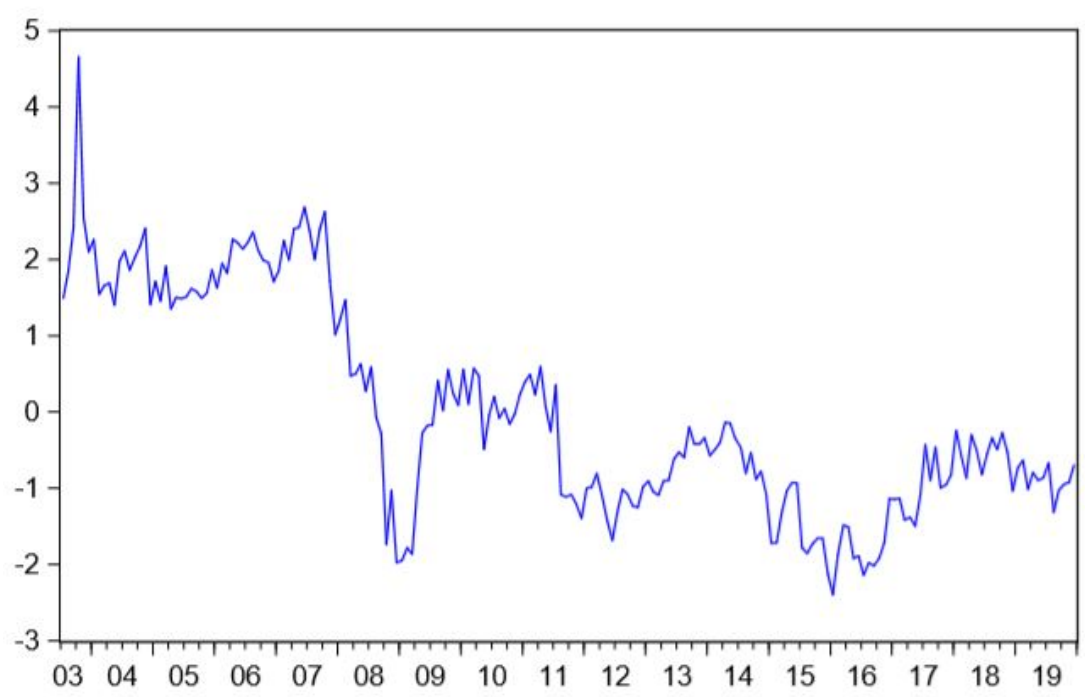

Figura A.2: Índice de Condições Financeiras - Canadá
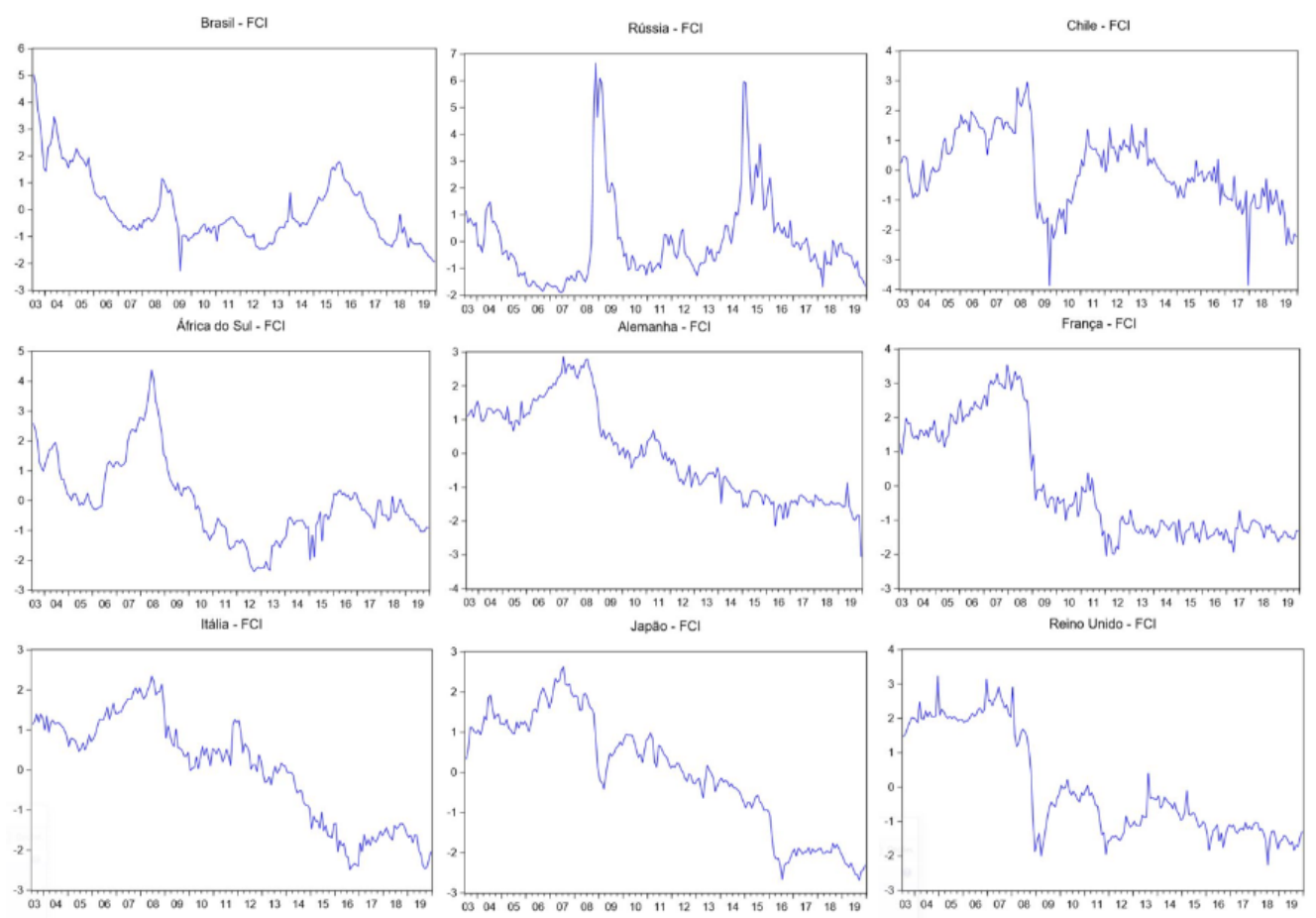

Figura A.3: Índice de Condições Financeiras - Outros Países 
B

\section{Função Impulso-Resposta (IFR)}
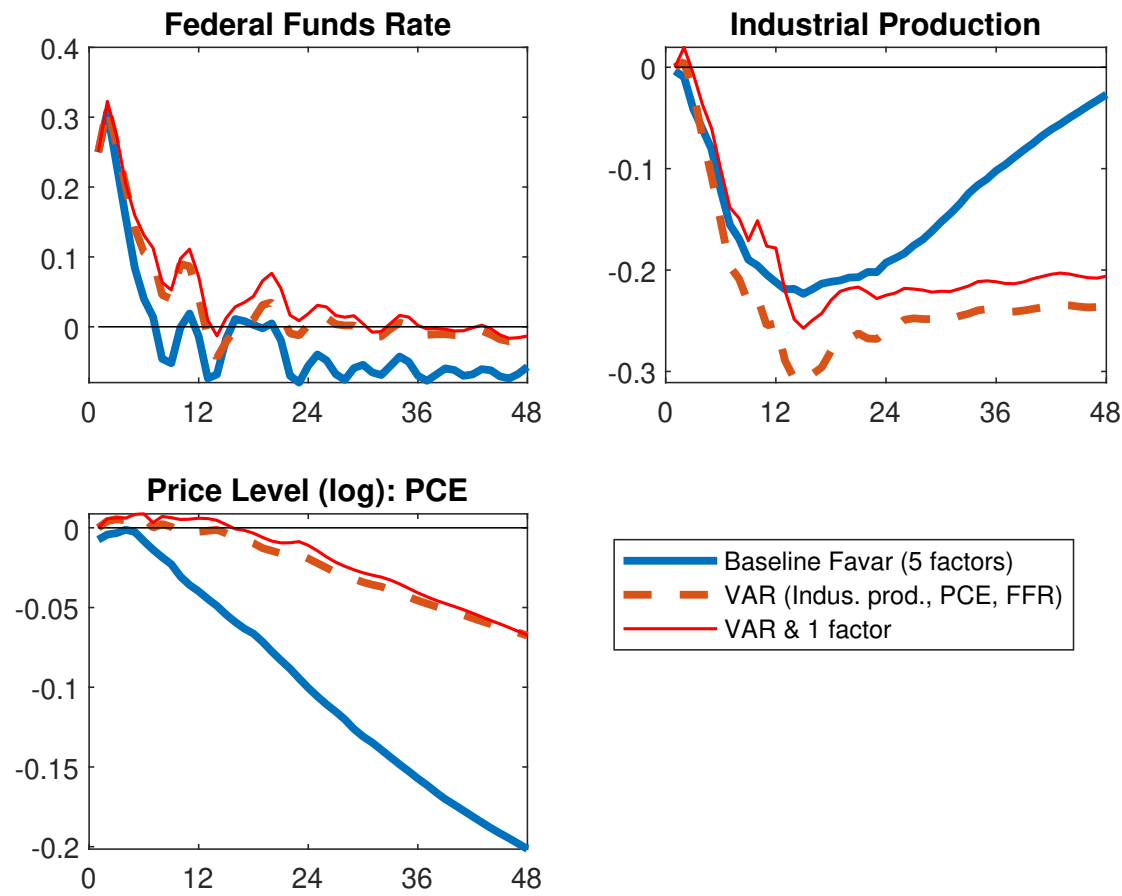

Figura B.1: Choque de Política Monetária Contracionista - com PCE 

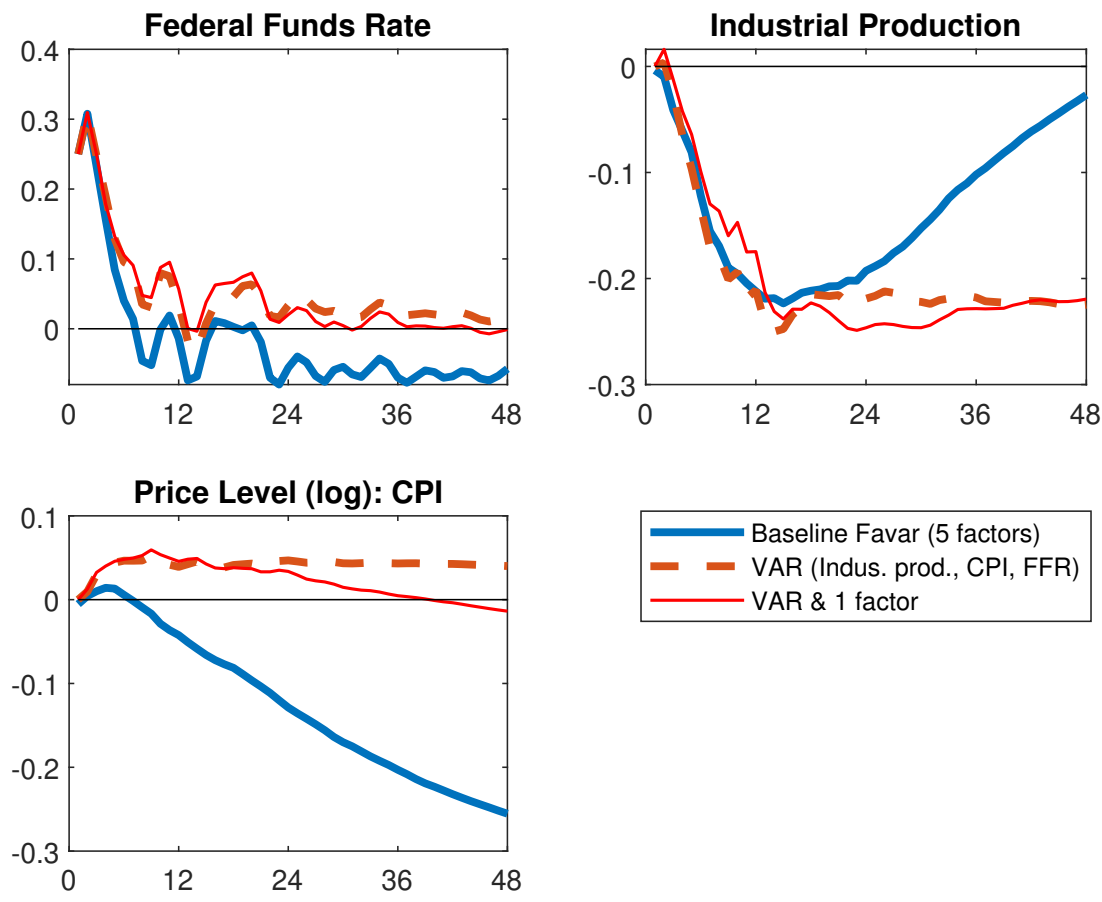

Figura B.2: Choque de Política Monetária Contracionista - com CPI
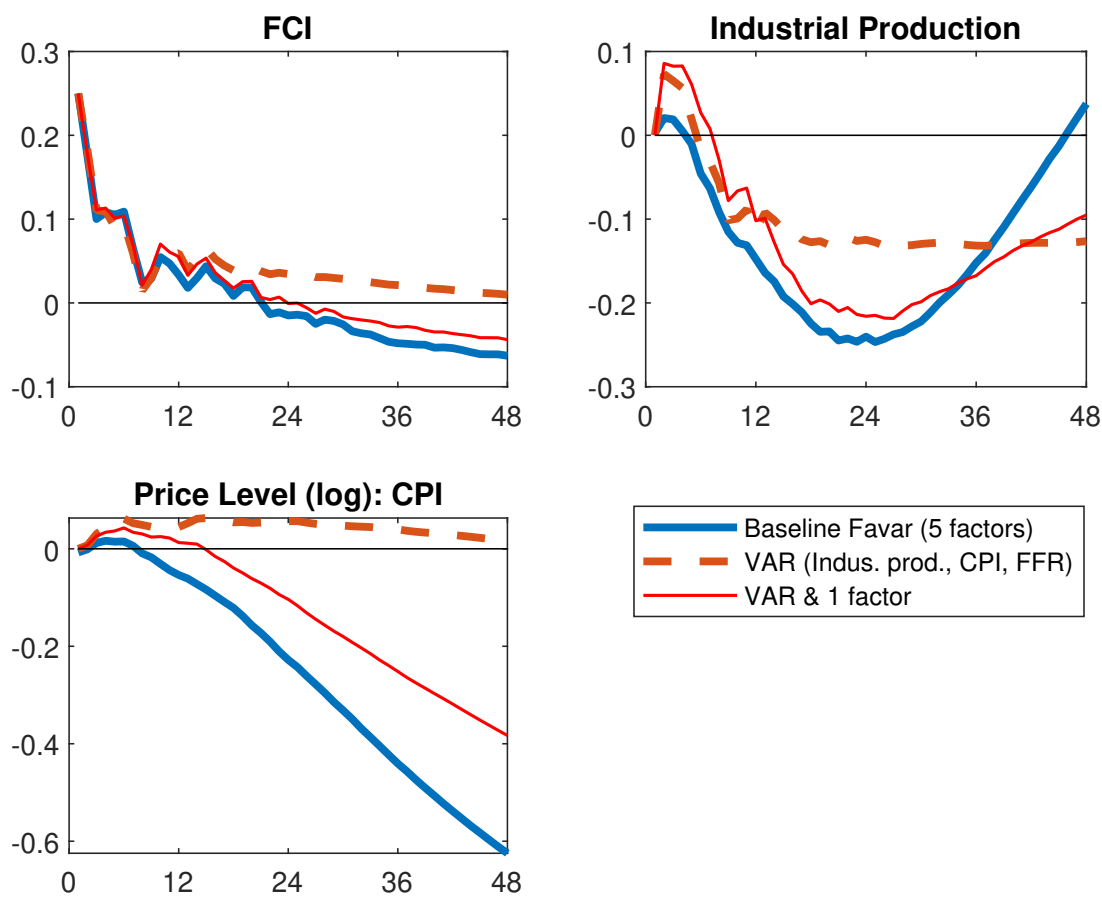

$$
\begin{aligned}
& \text { Baseline Favar (5 factors) } \\
& \text { VAR (Indus. prod., CPI, FFR) } \\
& \text { VAR \& } 1 \text { factor }
\end{aligned}
$$

Figura B.3: Choque Contracionista de Condições Financeiras - com CPI 

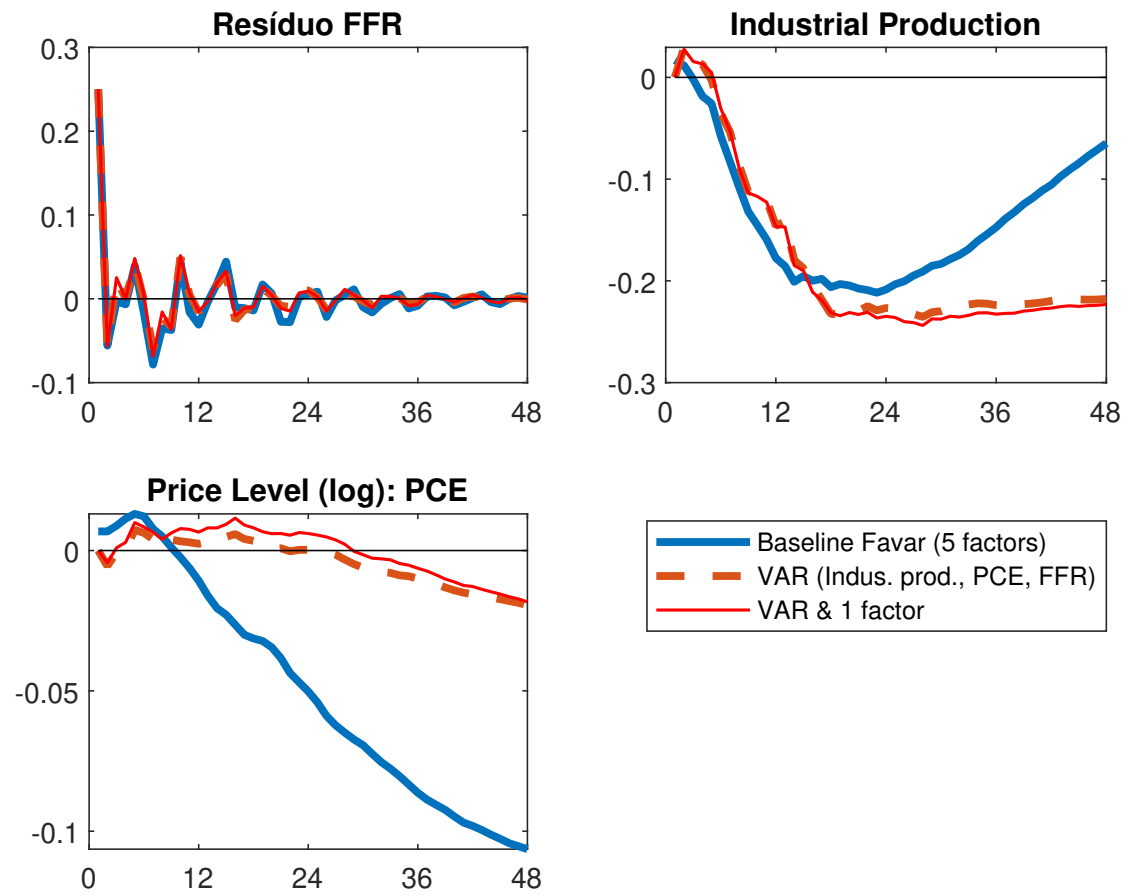

Figura B.4: Choque do Resíduo da Fed Funds Rate (FFR) - com PCE
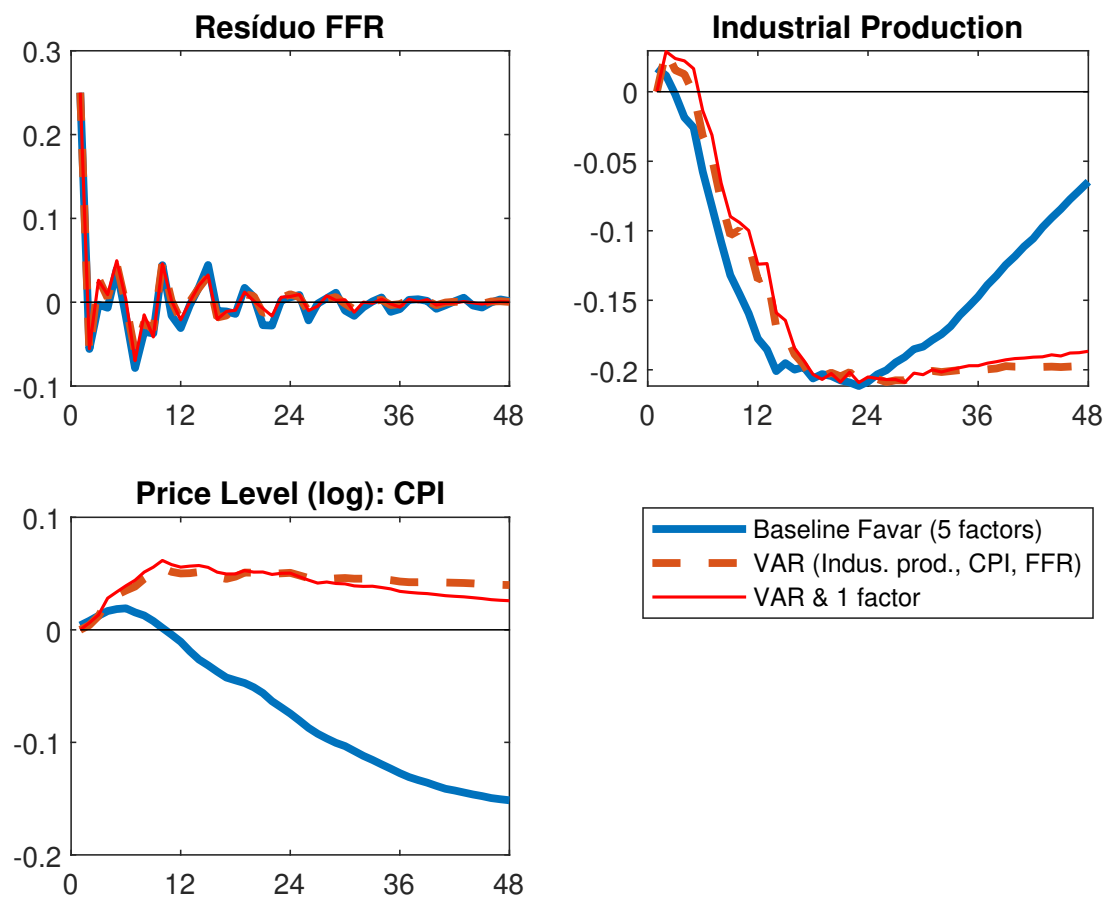

Figura B.5: Choque do Resíduo da Fed Funds Rate (FFR) - com CPI 

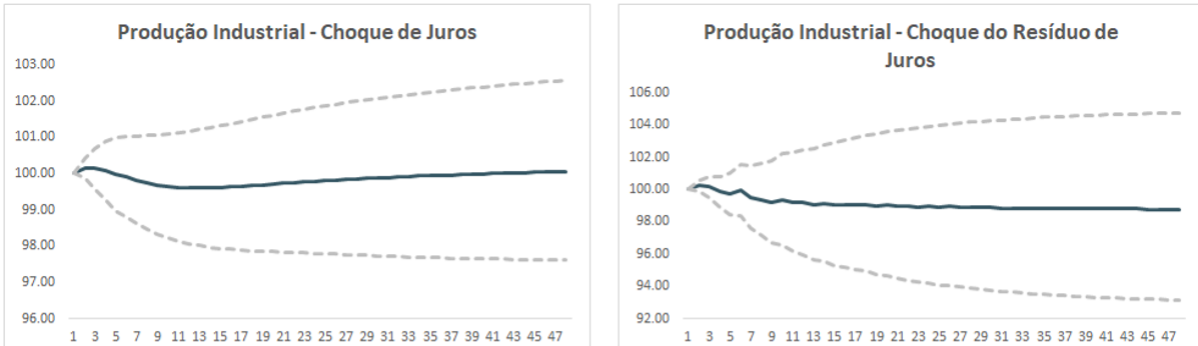

CPI - Choque de Juros

CPI - Choque do Resíduo de Juros
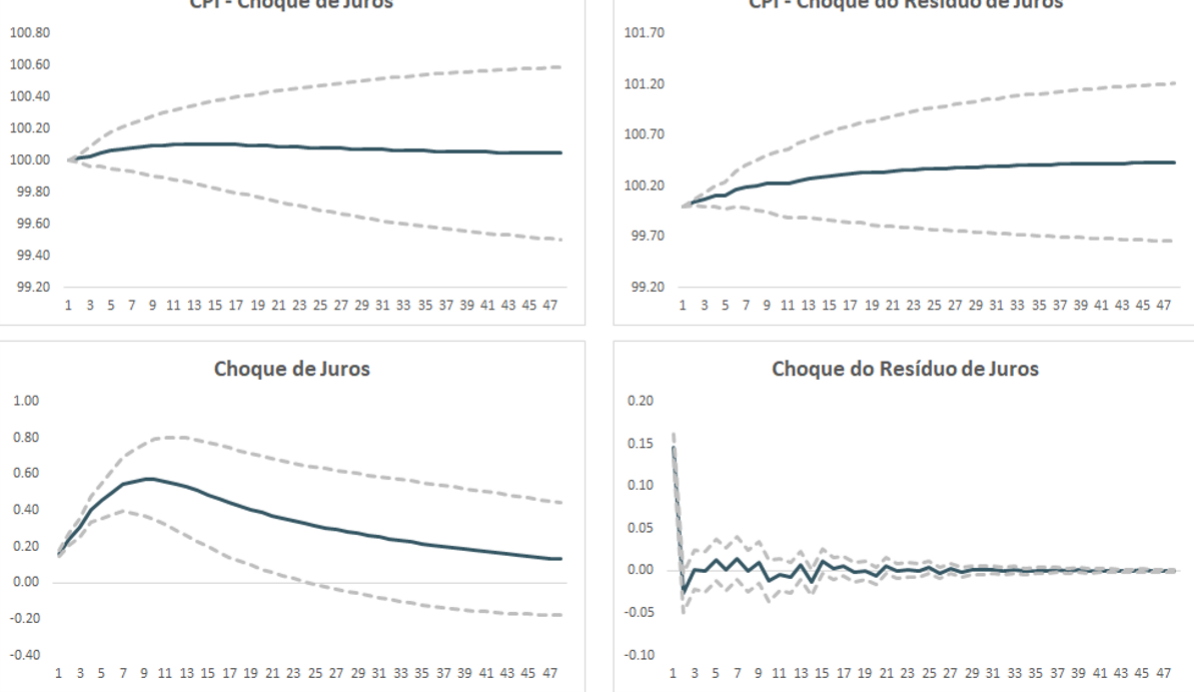

Figura B.6: Brasil: Comparativo entre um choque de juros (esquerda) e um choque de juros controlado para as condições financeiras (direita) 


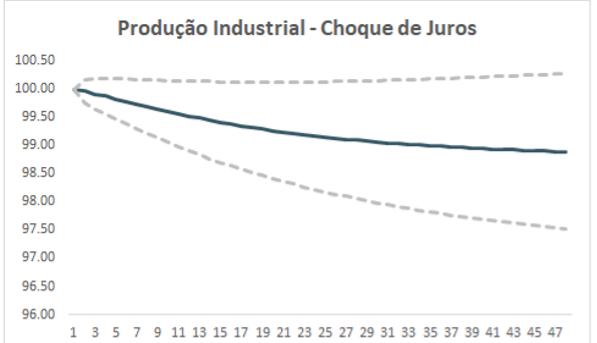

CPI - Choque de Juros

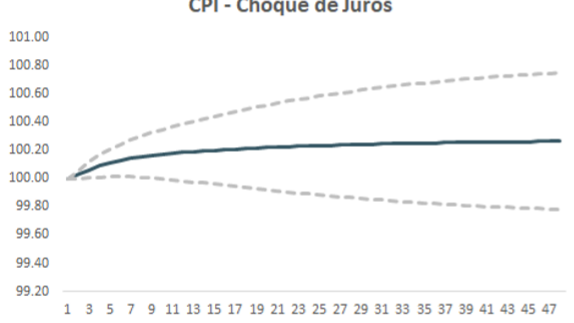

Choque de Juros

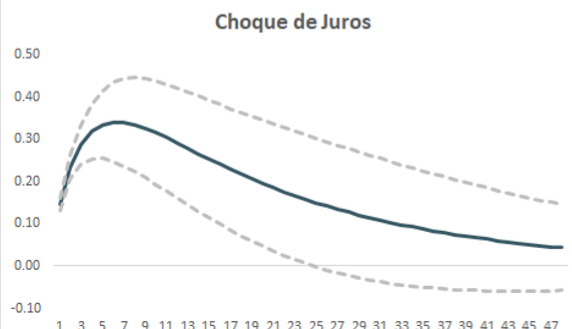

Produção Industrial - Choque do Resíduo de Juros

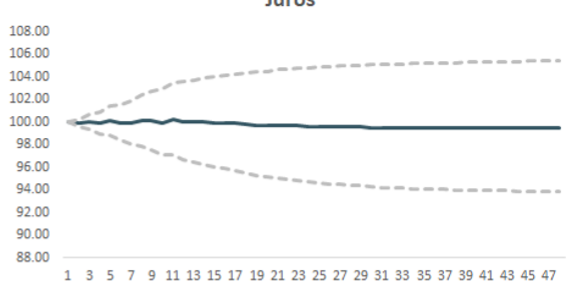

CPI - Choque do Resíduo de Juros

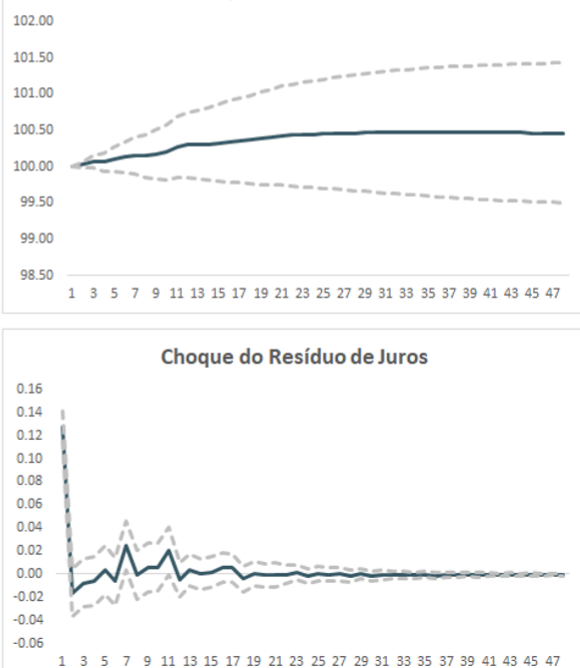

Figura B.7: África do Sul: Comparativo entre um choque de juros (esquerda) e um choque de juros controlado para as condições financeiras (direita) 